\title{
El dibujo es un verbo
}

\section{Drawing is a verb}

\section{JUAN (IVÁN) GONZÁLEZ DE LEÓN}

Instituto Nacional de Bellas Artes y Literatura - INBAL - ENPEG, Mexico

\section{RESUMEN}

Este breve texto procura presentar y poner en contexto imágenes de mi obra, busca también ahondar sobre el concepto de la poiesisl en la creación e interpretación del dibujo, así como su exploración poética procesual y gráfica. Comenta sobre algunos orígenes, rutas formativas y postura estética sobre el proceso y la idea fundamental de que el dibujo es pensamiento visual. Por último, aclara mi postura gráfica sobre la naturaleza de la imagen como una presencia poética, dentro de la cual percepción, realidad, lenguaje y pensamiento alternan posiciones. Imágenessigno, imágenes simbólicas e imágenes presencia.

\section{PALABRAS-CLAVE}

Pensamento visual, proceso, Poiesis, dibujo, línea, expresión gráfica

\begin{abstract}
A B S TR ACT
This text presents and contextualizes images of my work, seeking to deepen the concept of poiesis in the creation and interpretation of drawing, as well as its processual and graphic poetic exploration. It comments on some origins, formative paths and aesthetic stances on process and the fundamental idea that drawing is visual thinking. Finally, it clarifies my graphic stance on the nature of the image as a poetic presence, within which perception, reality, language and thought alternate positions. images as sign, symbolic images and images presence.
\end{abstract}

\section{KEYWORDS}

Visual thinking, Process, Poiesis, Drawing, Line, Graphic Expression.

1 Platón define el término de poiesis como la causa que convierte cualquier cosa que consideramos de no ser a ser. Aristóteles considera que mientras la poiesis consiste en la producción de una cosa diferente al sujeto, la praxis es una acción inmanente en la que el fin es la misma actividad. En mis procedimientos creativos, esta poiesis es un acto lúdico cuyo efecto es la forma en la que se abren los parámetros interpretativos y el potencial poético de una obra. 
Ya inmersos en la contemporaneidad y entrando a la segunda década del siglo XXI, las inercias de la modernidad y posmodernidad se deslizan entre las capas de la percepción actual respecto a la realización de imágenes y su producción. Aunque ya nos movamos de lleno en esta llamada metamodernidad1todavía reverberan los conflictos que se definieron entre la visión-percepción y la representación-convención de la vanguardias del siglo XX; y si agregamos la presencia formativa del ordenador y lo digital, junto con el cambiante panorama económico, veremos como se atomiza cualquier iniciativa de querer -si acaso es nuestro deseo- estabilizar una narrativa homogénica en cuanto al arte, su producción y sus procesos. El resultado es en las artes la presencia de un repertorio de opciones estilísticas, métodos y consideraciones estéticas amplias, como el hiperdibujo, el dibujo relativista y el contemporáneo.

Mi interés se sirve de los movimientos de arte procesual, Fluxus y el arte archivo. En particular concuerdo con el concepto de campo expandido y de la estética relacional, ambas me han llevado a ver mi obra como un obra en proceso o una obra abierta como sugería Umberto Eco. Mi obra es también una apuesta a otros métodos internos a la ingeniería de la visualidad y sus lógicas. Creo que si algo define al dibujante-artista-gráfico en el devenir contemporáneo es la necesidad de emplazar su obra sobre un plano conceptual que sobrepase el plano convencional del cuadro, que desborde la idea de un lugar ideal de la imagen y cuestione lo antropocéntrico. Mi procedimiento creativo, plástico y gráfico consiste en reacomodar material diverso que queda de los procesos en la producción de imágenes como vestigios, las cuales integro en montajes visuales. Contrario a la necesidad del estilo cerrado en una imagen clásica, la obra gráfica que presento está organizada como un sistema-esquema abierto a referencias, a corrientes interdisciplinarias paralelas al arte. Así, entre el esquema y el coleccionismo, los motivos que uso se proyectan sobre un espacio que sobrepasa una narrativa imperante y aspira a otros modelos de interpretación.

Así, si la definición habitual del dibujo es que es el arte de la representación ilusoria mediante la descripción y el uso de líneas, como dibujante-gráfico he procurado recuperar la segunda premisa frecuentemente desatendida en la operación dibujística: la proyección de la idea visual como un sistema. El dibujo como pensamiento e ideación y verbo².

Veo al dibujo como una "estrategia" de reconfiguración que desemboca en un texto visual. Los contextos en la actualidad son cambiantes y el peso de la experiencia que uno va acumulando también va generando acervos de conocimientos, lealtades epistémicas y vicios procesuales que se integran, se contradicen o se traslapan. Mi propuesta es trasmutar con ellos.

Debido a que vengo de una formación de ilustración científica, tardé en relacionarme al arte como expresión. Más profundamente lo sistemático de la ciencia, el análisis y el disfrute de

1 Se refiere a un conjunto de ideas que han surgido para compensar la inercia de la posmodernidad, en la que confluyen pautas del modernismo y el posmodernismo y abre un sentimiento distinto hacia el conocimiento, favorece la ironía y la idea de componer narrativas con combinaciones provenientes de diversas disciplinas. Una filosofía oscilante.

2 Artistas como Robert Smithson, Richard Serra y Sol Lewitt entienden el dibujo desde conceptos entrópicos, transitivos y procesuales. Serra sugiere que el dibujo ES y Lewitt lo considera un registro material del proceso conceptual. Los tres apuntan a que como experiencia el dibujo es gesto activo. 
desenvolverme en el entendimiento "lógico" de la imagen, como logos de la experiência dejaron una huella mis sentidos y premisas de mi obra. También en mi obra las referencias formales consideradas "clásicas" - debido a su atención en la forma- me han inspirado y más recientemente estoy trabajando sobre una obra que amalgama elementos neofigurativos con aspectos de una metodología conceptual, que combina residuos de figuración, abstracción y lo procesual 3 .

La cercanía con la biología dejó en mí una formación perceptual y una confirmación ética particularmente en la idea de que la realidad está hilvanada y de que en la naturaleza la condición de la vida siempre es fluida. La narrativa filosófica convencional es que estamos separados de lo natural; sin embargo, esta separación es errónea. Esta separación ocurre en el espacio del pensamiento. Sólo ahí es donde podemos separar lo abstracto de lo concreto, pero se nos olvida que este acto es apenas una maniobra del intelecto como herramienta de aprehensión temporal y no es definitiva. En este sentido, la naturaleza no se sabe enmarcada.

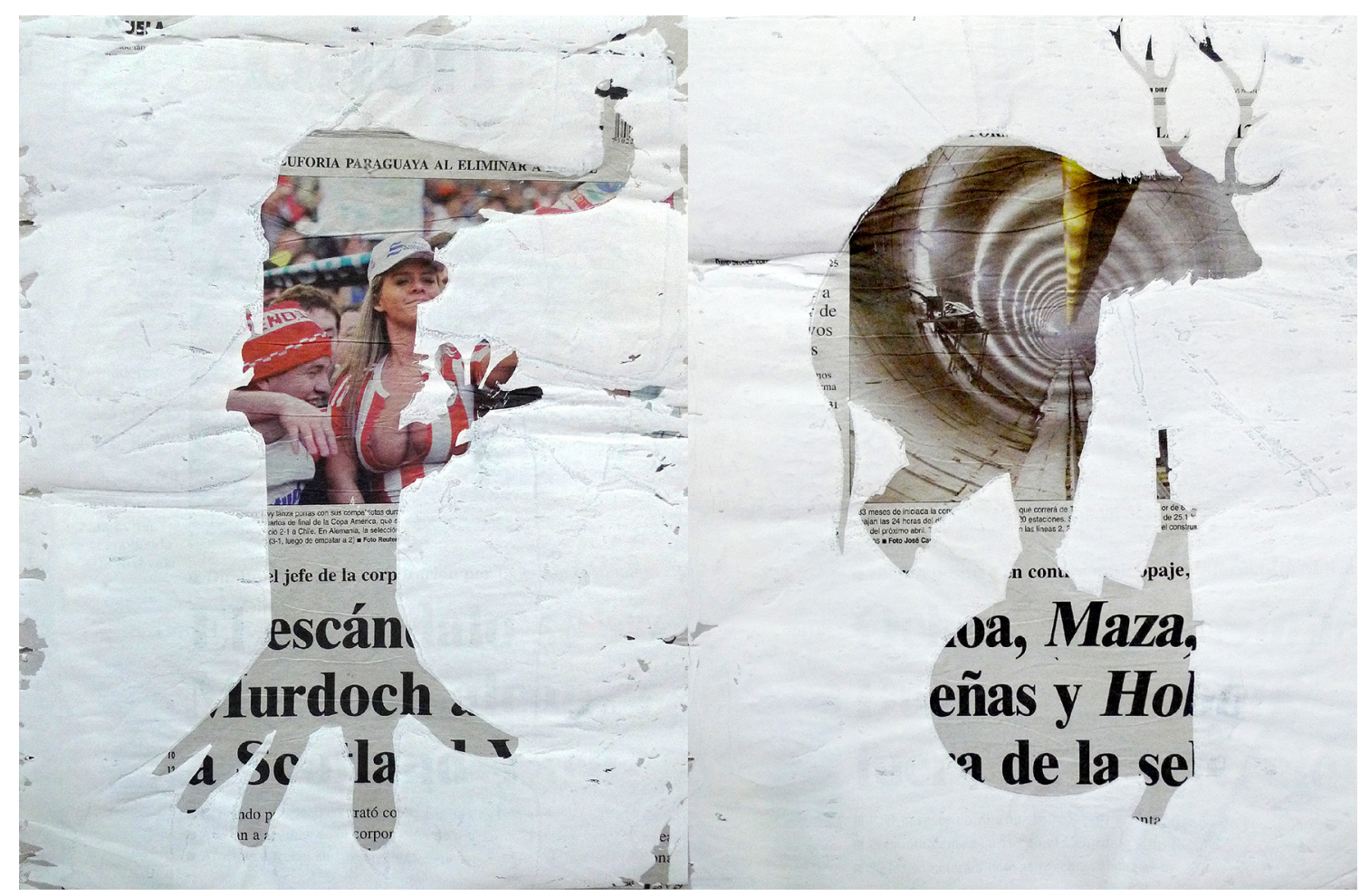

Figura 1 - Juan (Iván) González de León, 2010, Ecología cultural, Prensa apropiada, serigrafía, 40 x 60 cm. Fonte: Archivo del autor

3 Al final de los años cincuenta, el arte exploró las fronteras del objeto más allá de la pintura. Así se transitó del objeto hacia la idea, la lógica de sistemas y relaciones espacio temporales, develando que la obra también podía constituirse en procesos, sistemas y series (OSBORNE, 2002, p. 312). 
Mi contexto de trabajo fluctúa entre la Ciudad de México y el estado sureño de Oaxaca donde imparto clases. Como habitante de la capital, puedo decir que vivo en una selva de asfalto con una "ecología" cultural, multidimensional, afluente, pobre, moderna, rural, industrial, arcaica, multirracial, católica, laica, una megalópolis. La sierra de Oaxaca conecta con el mundo rural y Mesoamérica.

Los motivos seleccionados como signos vienen de una referencia a la flora y fauna plasmada gráficamente en productos. Una presencia, aún en la ciudad, de animales y anhelos trastocada por el acoso del capital, extraídos del ámbito de la metrópolis de una "ecología" urbana; así lobos, pericos, pegasos y otros motivos atestiguan el hecho de que aún al estar sumidos en una estetización como proceso de rarificación para aligerar nuestro devenir, existe en el interior un pulso biológico. Después de todo, somos seres sociales.

Como artista, y en lo creativo, me interesa definir y reconciliarme tanto con mi imaginario urbano como con una memoria histórica. De aquí que entienda y observe a la Ciudad de México como un ámbito, el cual opera como un escenario, un ambiente con sus espacios de ecología visual.

Quizá de manera sutil, mi contenido busca reponerse al proceso de cosificación avasallador y recuperar cierta dosis de inercia natural y poiesis. En mi obra la presencia de un personaje figurativo, semillas, sumados a la zoomorfía de estos elementos en una amalgama visual, son reflejo de nuestra condición continental. Me atrevería a decir "una necesidad americana" de seguir todavía hoy en día decodificando y reconfigurando nuestra realidad moderna y regional.

Estilísticamente retomo como referencias tantas morfologías como son posibles. También las tomo de mis visitas a zonas arqueológicas. Asimismo, los conceptos de la postmodernidad -como son la apropiación, la hiperrealidad o la cita intelectual- son recursos conceptuales en la ciudad. También lo son el remiendo, la sustitución de los objetos para proteger el espacio del auto (latas de pintura, botes grandes, cajas, trozos de lo que sea), los "diablitos" de luz (trampas para colgarse de los cables de luz sin pagar) o los objetos que quedan colgados en cables son pautas y referencia plásticas procesuales, instructivos, metáforas políticas y enseñanzas instrumental y "técnica". La ciudades latinas ofrecen un espectáculo de opciones que mezclan lo moderno y lo rural. Pongo otro ejemplo, durante años no entendí la diferencia entre el chorreado del asfalto líquido y la técnica de "dripping" de Jackson Pollock. Sucedía que era el mismo método, el espacio de legitimización definía cuál era un arte o un recurso empobrecido.

Habito en esta condición procurando dar sentido al espacio derrideano, la inercia de la mirada contemporánea y la apropiación de imágenes y su negociación en un texto visual. Así, quizá, pueda acercarme a esa "naturaleza" que se nos escapa dentro de esta condición hiperreal.

En lo simbólico de las imágenes y en lo fundamental, en un sentido mi obra representa una narrativa que abarca lo inmediato y, en otro sentido, una necesidad "trascendental". Visualizo la idea de que somos una semilla tragada por el ave que en un ciclo amplio de vida sólo es regresada a la Tierra para convertirse en diferentes signos. Cada signo constituye un distinto estado de conciencia. 
Devenir, transmigración, reciclaje, transmutación, normadismo, no son sólo conceptos dentro de los que me sumerjo académicamente. También soy acompañado y transpirado por mi formación cultural semi-occidental, no codificada pero que impera de muchas maneras. Por ejemplo, de niño me divertía hipnotizarme con el rechinado de la máquina de tortillas, memorizar la palabra "nixtamal", de hecho tengo mi piedra para moler maíz par hacer frottages sobre una mesa. La insistente presencia de economías paralelas, la improvisación de la necesidad en la pobreza y la aún mágica y terrorífica intensidad de lo rural, la cultura mexicana popular son parte de la estructura de mi psique y métodos de sobrevivencia y vivencia.

\section{El contexto, la obra grafica y el dibujo}

El testimonio de estas influencias se evidencia en el frecuente uso de la imagen emblemática de mi personaje Hombre-ave, en las imágenes populares y la línea franca de la forma mesoamericana, así como de la nota de la figuración popular tanto en la representación como en los motivos simbólicos. Estas fuentes sostienen mi investigación y son la causa de que mi propuesta artística integre una reflexión central sobre tres aspectos: La idea de que nuestra manera de representar en Latinoamérica y en México suma una noción diferente de la percepción que tenemos del espacio tiempo; Que en el que hacer cotidiano de nuestros modos de producción se devela una iconografía, métodos y como resultado una estética que está permeada y transita por ritos de autorregulación compleja de la subjetividad, y que es, en esta rotación de signos, lo que se percibe y se define como México subterráneo; Como productor sensible a mi entorno noto que los procesos en México son rizomáticos ${ }^{4}$, no se cortan de tijeretazo sino que se traslapan y llevan a cuestas de manera simultánea esperando la oportunidad para ser insertados en el tejido de la realidad.

Actualmente estoy trabajando sobre una serie de dibujos dispuestos para ser reproducidos en gráfica bajo el titulo: "La obra como huella marca y símbolo, Zoomorfias". Estoy integrando el dibujo, la gráfica y el proceso plástico como son el monotipo el collage, el intaglio dentro de un esfuerzo integrador que concibo como pictografías 5 .

4 Deleuze \& Guattari desglosan los modelos lineales históricos y plantean alternativas en la forma del rizoma, modelo de crecimiento orgánico. Abandonan así el modelo dicotómico en favor de uno multifuncional, así "the rhizome is made only of lines: lines of segmentation and stratification". (DELEUZE; GUATTARI, 1983, p 48).

5 Los pictogramas antecedieron la escritura. En la actualidad es entendido como un signo claro que esquematiza un mensaje sobrepasando la barrera del lenguaje. 


\section{Consideraciones sobre la condición perceptiva en la realización de estas imágenes vistas como lenguaje, realidad y pensamiento}

En la tradición bioscópica, la condición de observación científica de reflejo y semejanza, así como la implicación de una simetría entre la vista que registra con el motivo observado (mímesis) en parte es certera cuando es análoga. Sin embargo, en las artes la noción metafórica del uso del lenguaje subvierten esta noción y el ver se torna en observar, otear y mirar. ¿Cuántas otras formas de hacerlo hay? Es en esta instancia que el acto de usar la vista rechaza ser solo una función instrumental.

Impulsos, no racionales, emotivos, espirituales sesgan esta primera intención de únicamente reconocer, convirtiendo, así, el acto de mirar en un pulso distinto, en la posibilidad de recrearse en lo que uno mira uno mirándose. Es en este espacio dentro del cual sucede una metabolización de los sentidos y la quimera de la imaginación.

\section{La simbología de la lógica: un sistema dentro y por fuera de sistemas}

Si el pensamiento se manifiesta a lo largo y ancho de un espacio imaginario es también en este desplazamiento de la mente que el "ojo" se mueve en dirección de un sistema de signos. Dentro de estos confines, los conceptos de espacio y tiempo se modifican. Cosas reales se vuelven ficción o "parecidos". En este sentido, el advenimiento del modernismo desplaza la observación de la vista mimética por otro instrumental conceptual para percibir con la mirada de una forma más analítica y así configurar un lenguaje distinto, como herramienta para abordar la "realidad". Esto en el caso de las escuelas analíticas, no olvidemos las vertientes del surrealismo como contra propuesta. En la actualidad transitamos por un concepto de un mirar, dígase, "estratégico", porque miramos con estrategias de procesos de deconstrucción y resignificación más alineados y entrenados por el pensamiento posmoderno y conceptual, que provienen del método de deconstrucción del estructuralismo y de los analíticos conceptuales: Michael Foucault, Gilles Deleuze, Jacques Derrida, Rosalyn Krauss y Roland Barthes, entre otros. En cuanto a mi influencia latina, encuentro inspiración en Octavio Paz, Jorge Luis Borges y Jaime Sabines.

Estas inclinaciones posmodernas me han influenciado de tal forma que al trabajar mis imágenes reconozco un valor en el proceso. Podemos sintetizar el dibujo de manera contemporánea a partir de la marca, la huella y la tensión entre el signo y el símbolo6.

Al crear mi obra voy haciendo, durante el proceso de simbolización, conexiones sutiles que trasmutan, ajustan el proceso y definen la dirección del trabajo final y a su vez marcan inclinaciones narrativas abstractas o estéticas. Como obra acabada me interesa dejar a la vista el signo como una imagen que flota entre algo prelingüístico y su devenir en símbolo, procurando dejar latente la interpretación sin cerrar el circulo de significación.

6 En la comunicación los signos aparecen en estructuras ilógicas y es en su tránsito que adquiere carácter simbólico. El símbolo exterioriza un pensamiento o idea. Aristóteles decía que no se piensa sin imágenes. Como figuras de discurso en la actualidad en el diseño y la semiótica se usan en el orden de ícono, indicio y símbolo (LUPTON, 2012, p.89). 
Mi proceso conjuga distintos estados de representación. Aunque comience o me identifique con una imagen exterior, frecuentemente busco reconciliarme con una imagen que describa y proyecte una idea de la realidad; una confluencia entre idea e imagen que opere como sustitución de la realidad misma. El resultado es "leer visualmente" la realidad como un texto. Una realidad hecha de elementos imaginarios. Esta idea tiene sus referencias en diversas alusiones al cómo se va encadenando la ruta de significación para generar contenidos. Wittgenstein, en su texto Logico-philosoficos, menciona el triángulo perceptual entre pensamiento, lenguaje y realidad 7 . En este sentido, al comenzar desde la lógica del pensamiento para realizar obra, la imagen deja de ser un simple reflejo de la realidad para convertirse en una configuración de la misma. Es decir, se empieza por copiar, se define un signo y se transita por consenso al espacio simbólico. Más allá de la referencia: los signos -como cosas o referencias estéticas- cierran aparentemente el triángulo. Sucede dentro del ámbito de lo lógico aunque sucede fuera de él.

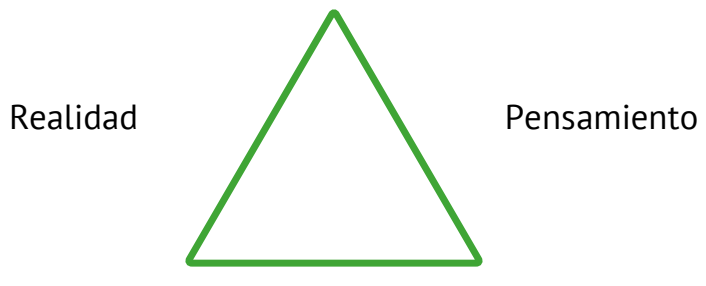

Lenguaje

\section{Los símbolos como presencias}

Las instancias se dan en el proceso de pensamiento que están sensiblemente percibidas como experiencias sinestésicas. Pensar, dar forma e imaginar constituye un todo unificado con salidas, nexos y vasos comunicantes. En resumen, tomo, reconfiguro, proyecto. Recojo una marca, sigo su huella y la reconstruyo en un pensamiento de una imagen de la realidad. En el dibujo podemos seguir el registro y ver el inicio del acto de invocación y tener visiones.

Ahora bien, las ideas de estructura y proceso en mi obra están en continua alternancia. El ideal sobre la imagen contra la inevitable relación isomórfica con la realidad, hacen que inevitablemente negociemos nuestras expectativas con los confines de la experiencia. La experiencia del hacer implícito en lo procesual sugiere nuevas rutas de proceder así conforme se devela y revela la imagen; uno se va a encontrar con el hecho que hay procesos de adaptación

7 Wittgestein plantea que existe una relación entre tres puntos donde el lenguaje es concebido como una imagen de la realidad que define lo que se piensa. La imagen es un modelo de la realidad (AGUILAR, 2008, p. 307). 
misma en el acontecimiento del ir "haciendo". Por esta razón, dibujar es a su vez un "verbo", como sugiere Sol Lewitt, o una línea sacada a pasear, como decía Paul Klee. Es también la razón por la cual los antropólogos no se reconcilian en cuanto al definir al dibujo como una escritura, o a la inversa. Dentro hay una dualidad y así es que concebimos la idea de concebir al dibujo como una estrategia visual como una imagen, pongamos, por ejemplo, el pictograma.

En el libro Esto no es una pipa, Foucault comenta sobre el caligrama; en la obra de Paul Klee caligrafía y diagrama están relacionándose en su obra, se da una "alfabetización" de los recursos sintácticos junto con la presencia de su iconografía. En el arte contemporáneo Jean Michelle Basquiat representa esta vertiente insertada en la cultura de Wall Street de los años noventa del siglo XX.

En este punto me refiero a una confusión que existe frecuentemente entre la noción de una imagen como ideal o modelo y una ilustración descriptiva. Esta distinción me ayudará a describir con mayor eficacia el recorrido formal del desarrollo de mi obra.

Toda imagen representativa pasa por ser: 1) Por la descripción copiada de lo que el ojo registra (copia); 2) por el signo y la representación de ese motivo con sus rasgos naturales, dados en sí mismos (natural); y 3) por el símbolo; una modificación de sus sentidos con diferentes alcances, sabiendo que estos sentidos no son naturales sino contextuales y consensados (no natural).

Así es la relación entre la idealización de una imagen y su contraste con su uso descriptivo. No es lo mismo el ideal de la forma de una rosa siempre de color roja, a su ilustración científica con sus detalles. Ocurre lo mismo al modificar el balance entre signo y símbolo.

Vista la naturaleza de la imagen como un sistema de signos o un sistema de sistemas de signos es entendible por qué hay diferentes obras con distinto valor, resonancia o impacto. En este sentido, cito a Fernando Zamora Aguilar: "Toda copia tiene un potencial sígnico, todo signo tiene un potencial simbólico. Todo signo es una copia que amplio sus sentidos establecidos, y que se abre a todos los sentidos posibles así cada momento implica un enriquecimiento y supone al anterior" 8 .

\section{Entre la lógica y la perepción simbólica y la experiencia}

Esta ruta, entendida como "relativista", implica explorar la relación lógica de las partes, adentro del espacio de representación, y al sumergirnos en la experiencia de la visualidad observamos que hay una tensión frágil entre imagen (veraz, visual y presencial) y los posibles cambios en su evolución como imagen simbólica. La primera es de tipo perceptual; la segunda, de tipo vivencial. Toda imagen tiene así una plusvalía simbólica, sujeta a ser vista e interpretada. De aquí, la idea de que en la posmodernidad el arte se inclinara en la dirección de ver la imagen de una manera que incluyera la percepción de lo social. Así mientras en la modernidad predominó la forma, la expresión y la estética, la posmodernidad favoreció la interpretación del ícono, el indicio y el símbolo, y abrió camino a múltiples experiencias culturales, sociológicas y formales.

8 En la filosofía de la imagen el autor Fernando Zamora Aguilar menciona cómo el proceso de conceptualización de la imagen va mutando a través del signo y el símbolo y se hace presencia (AGUILAR, 2008, p.312). 


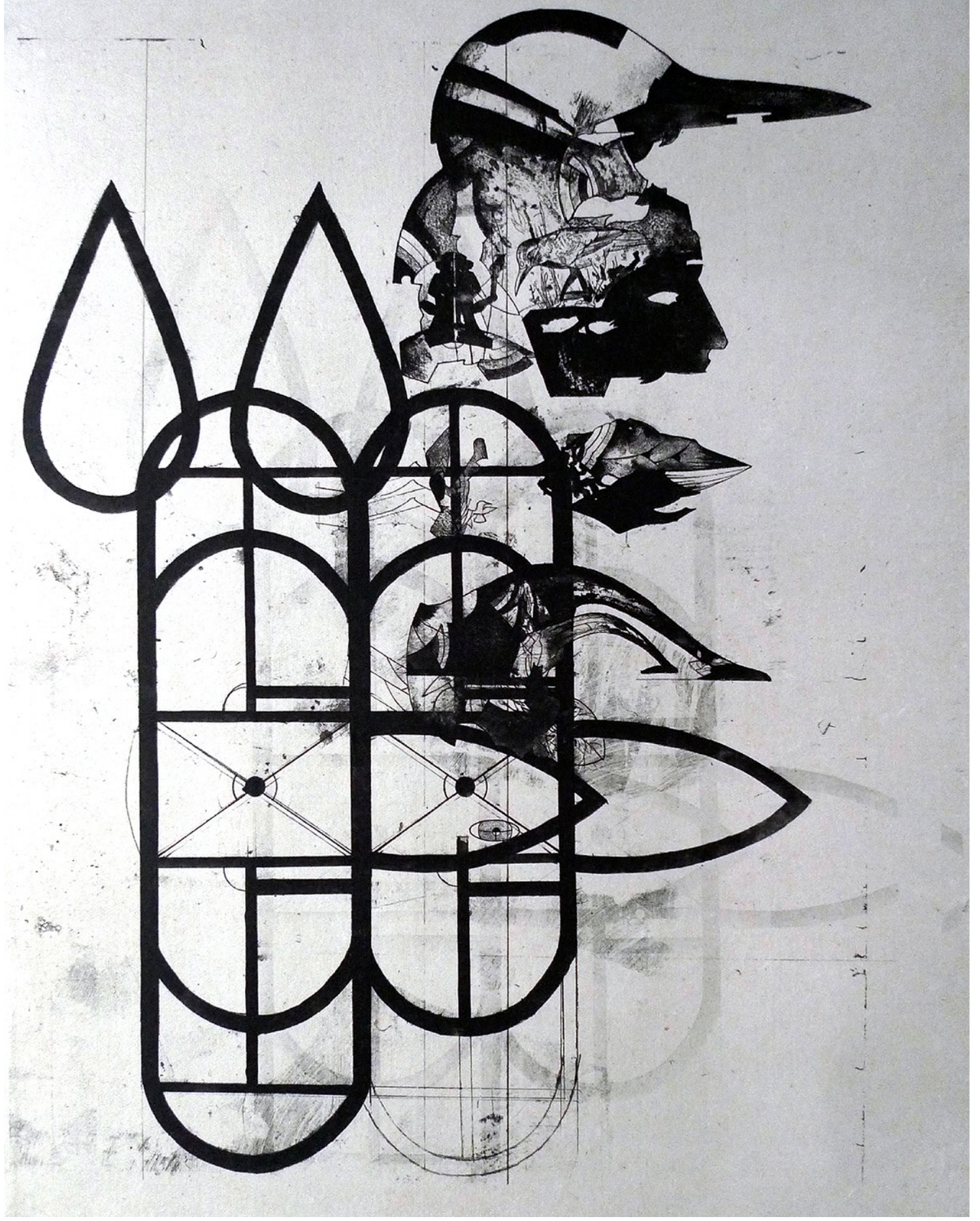

Figura 6 - Juan (Iván) González de León, 2020, Perfil y resonancia. Impresión digital sobre papel kozo sobre tela y bastidor, $60 \times 45 \mathrm{~cm}$. Fonte: Archivo del autor. 


\section{La praxis en contexto}

Ahora bien siendo productor y no filósofo me pregunto si ¿la creación frecuentemente rebasa las rutas o parámetros de el discurso? Mi respuesta es sí. ¿Es fundamental el pensamiento científico o la representación filosófica en la creación de obra? Mi experiencia me dice que enriquece pero que no. ¿Es posible fusionarse con la experiencia estética sin tener referencia al signo, en lo simplemente vivible? Creo que sí. Esto sucede cuando se sumerge uno en la experiencia del proceso y no meramente en el método o la técnica. El arte como experiencia presupone el hecho de que uno se abandone de manera readaptativa a la experiencia, como la improvisación en la música. En conclusión pienso que fluimos por estas instancias nutriendo y dando cuerpo a la obra; sin embargo, pienso que cada persona da un énfasis a una inclinación. En esta dirección se abren otros ámbitos en cuanto a la experiencia de la creación de las imágenes. También sucede lo mismo con la reconfiguración de los signos y los símbolos en el proceso de semiósis y nos adentramos -contemplativamente- en la relación con la imagen como presencia.

\section{La imagen como presencia y no meramente representación}

En este terreno se encuentra frente a frente uno con el símbolo como una función anagógica entre lo visible y lo no visible?.

Mi trabajo se centra en los símbolos hierofónicos, el cielo, lo elevado, lo poderoso e inmutable, la muerte y el renacimiento... La semilla-el hombre-el aire; surgimiento-desarrolloreintegración, representado como un mantra visual interno de regulación ontológica. Estas son experiencias anagógicas. Realces de imágenes terrenales hacia lo enaltecido de las experiencias.

Bajo este estado como un "no símbolo" sin la verbalización, sugiero que las imágenes que pasean en mi mente se constituyan no en representaciones descriptivas de las cosas, sino más bien en signos flotantes, en un texto-visual.

Todo lo que acontece dentro de una imagen representa un logos latente que quiere manifestarse que, como indica Ingar Gadamer, la imagen simbólica incrementa el ser. Así, me interesa explorar el aspecto del doble sentido que tiene la naturaleza del símbolo; la del "doble sentido" 10 que considera un símbolo no lingüístico, residuo que opera y tiene lugar en actividades prelingüísticas, aquel que flota entre lo vivo y el conocimiento (bios vs logos). Considero que la invitación a la experiencia vivencial, como elemento protagónico en la realización de obra, acentúa esta tendencia, ya que espacio-tiempo fluyen entre sí y no se separan de la obra como sería bajo otros esquemas o en las tendencias clásicas de producción que organizan el proceso en etapas escalonadas, como la clásica. Al subrayar la idea del arte como experiencia podemos amortiguar un poco nuestra tendencia a la idealización o un método programado y proveernos de mayor

9 Anagogía es la experiencia de realzar las cosas hacia el espacio de lo ideal o el mundo, en donde Platón suponía todo se originaba. Dentro de este texto, mi intención es identificarme con una manera de mirar que supera el signo y transita por lo simbólico aún con referencia exterior, pero sube a la imagen invisible una hierofanía.

10 Me apropio de este concepto para identificar la experiencia que se da al superar lo reconocible y pasar a una experiencia distinta, esto ocurre al abandonar las semejanzas y uno se adentra en las visiones. 
creatividad y ligereza creativa. John Cage, Cy Twombly y Joseph Beuys comentaban acerca de lo aleatorio en la composición y la fortuna en el gesto y lo orgánico como proceso en la obra. Por su parte, Robert Smithson quería invitar al tiempo geológico en contraste con el tiempo cartesiano en su espiral en el desierto.

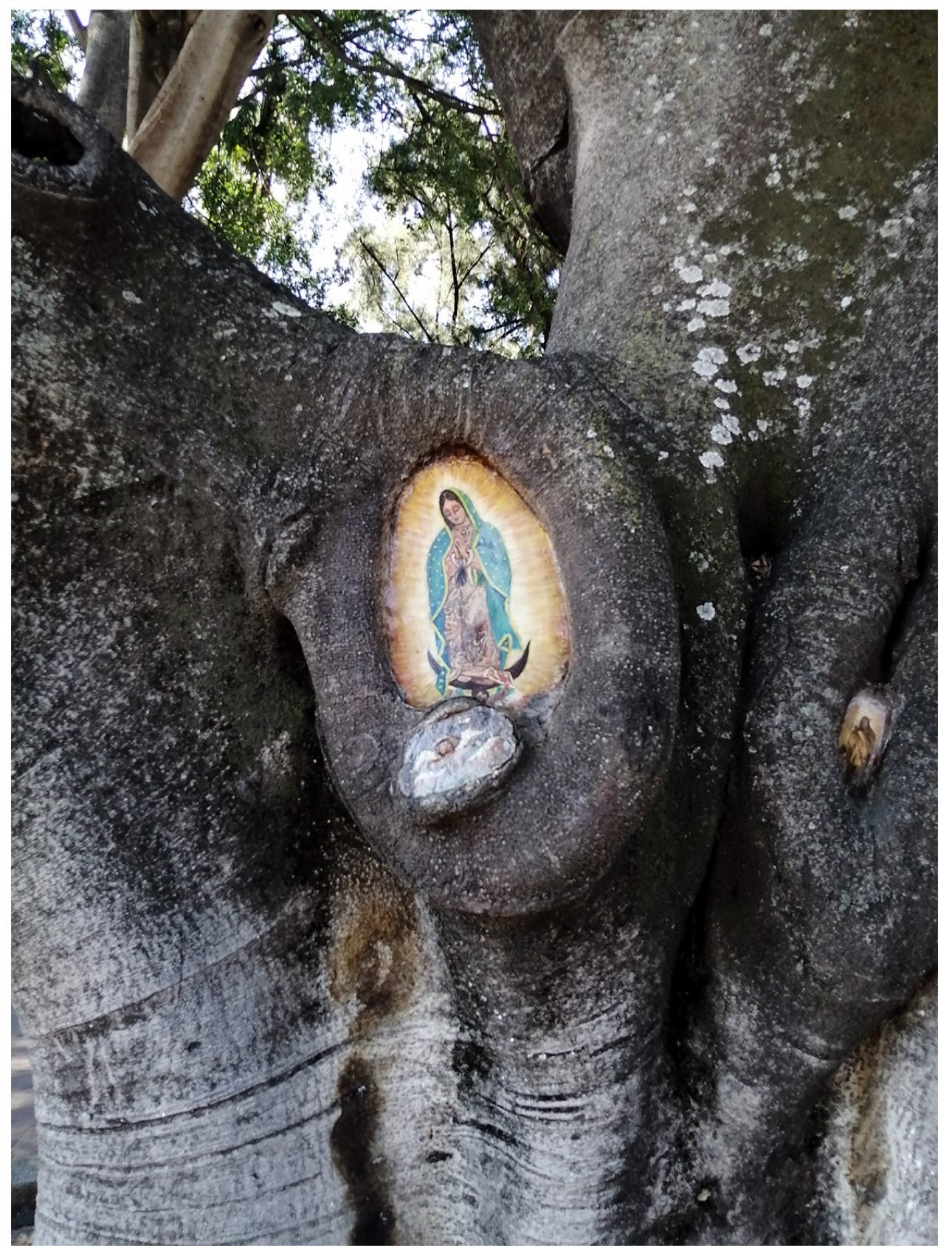

Figura 7 - Juan (Iván) González de León, 2020, Virgen en nudo de tronco. Técnica mixta sobre cortesa de árbol, $50 \times 50 \mathrm{~cm}$. Fonte: Archivo del autor 


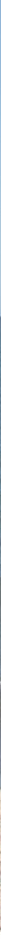

Figura 8 - Juan (Iván) González de León, 2008, Capa Mar de Cortés, lona, espejo, madera, bocina, mp3, baterías, impresión vinyl, 180 × $180 \mathrm{~cm}$.. Fonte: Archivo del autor

\section{Una simbología de la desemejanza}

La primera parte de este texto se ocupa de una serie de comentarios nutridos por mi formación académica, esta parte proviene de mi experiencia, que me ha gradualmente movido hacia una investigación con cierta dosis de semiótica, así como un uso de elementos figurativos y procesos abstractos.

Durante varios años he explorado al dibujo como herramienta de representación, ya sea mimética, abstracta o lingüística. Concibo esta obra como actos y/o estrategias de ensamblaje que resumen lo que conozco de el dibujo. Para mi sorpresa, me he encontrado afirmando recorridos formales muy antiguos así como disolviéndome en nuevas rutas perceptivas. Por ejemplo, en una sesión de trabajo expliqué cómo había abandonado las referencias directas en cuanto a motivos visuales y enfocándome más en la composición, inevitablemente, y sin querer, fui minimalizado aún más el proceso. El resultado fueron dibujos más sintéticos, que se hacían manifiestos por su 
silencio, su cuerpo y delicadeza sin referencias a algo narrativo. Tampoco eran expresivos ni hacían uso del espacio bidimensional ilusorio, los sentía, no los veía, parecían microesculturas, se hacían presentes en el espacio con autonomía. Entendí que la ruta de representación me había llevado de la huella a la marca, al signo y al símbolo, pero que me acercaba a la imagen como un asunto conceptual, perceptual y hermenéutico.

Descubrí una especie de teología “negativa”. En ella, la obra más que parecerse en concreto a "algo" sugirió más bien a qué no se parecía. Uno abandona relativamente los confines de lo sígnico para transitar rumbo a una experiencia simbólica anagógica. El resultado fueron obras que potencializaron lo gráfico, en el proceso me despegué del dibujo de representación y se manifestó el grafos ${ }^{11}$ de la obra.

\section{La cultura sensorial, otras rutas de conocimiento}

Mas allá de la referencia, los signos y los símbolos como cosas o como presencias han sido recientemente la motivación de mi obra, ya más inmersa en el proceso y la síntesis. Sin embargo, no ha sido suficiente desarrollar formalmente solo mi sintaxis, también se han planteado aspectos de tipo semántico más complejos. Estrategias, retóricas me motivaron a cuestionar otras salidas y a explicarme las consecuencias de atender elementos visuales de México, así como experiencias paralelas al circuito de las artes. Tuve que repensar el dibujo a partir de la noción de que éste podía simultáneamente funcionar como un proceso cultural con una iconografía local. En la inercia de Occidente, por ejemplo, pensar o imaginar una planta es en sí formarse una imagen de ella, no es relacionarse con ella ni con su contexto o naturaleza; sin embargo, en las culturas de las naciones originales de Arizona, Estados Unidos, como sería la Hopi o en distintas culturas indígenas aún vivas, como las del estado de Oaxaca en el suroeste mexicano, no sucede así. En estos espacios -y agregaría: en estas velocidades del pensamiento que a veces parecieran aletargadas- pensar una planta "es" relacionarse con ella y sus confines perceptuales, míticos y sutiles. No se aísla uno del espacio real o abstrae uno el objeto de sus efectos en el entorno, de aquí que invocar visualmente esté fusionado con el objeto y que el hacerlo sea en sí "tocar el mundo natural", que mejor evidencia que la línea autógrafa del maestro Francisco Toledo ${ }^{12}$.

Estas experiencias, que se combinan con la presencia de imágenes, ocurren todo el tiempo en México; las vírgenes en los codos de los árboles, los colguijes en los árboles de los manantiales de los pueblos dan testimonio a estos deslizamientos voluntarios y subjetivos; un traslape entre lo funcional y lo sensible. En estas culturas, lo objetual, el rito y los sentidos alteran

11 Me resulta interesante que el término grafos, además de la imagen, también pueda relacionarse con las ciencias. Un grafos es un conjunto de objetos llamados nodos unidos por arcos. Esta definición abre el concepto de dibujo en el que una sucesión de puntos es una línea y comprueba que el dibujo es un pensamiento visual.

12 En alusión a la obra de Toledo, quisiera mencionar que entre las virtudes del pintor oaxaqueño como artista gráfico estaba la compleja investigación en torno al uso de la línea. Como dibujante exploró el achurado clásico, la línea de Durero e integró la caligramática de Paul Klee, y a su vez logró traducir la línea cruzada del petate, del filo de las cactáceas y la morfología de múltiples animales. 
la resonancia en el funcionamiento del cuerpo, de tal forma de tal forma que los lenguajes verbal o visual estén conectados con el estado de ánimo. La obra visual revela sintonías y sincronías, siendo éstas también cosas en el mundo. Las imágenes son parte del mundo, la imagen en el mundo prehispánico no es algo que se presenta en sí como fin, más bien funciona como un vehículo, es una membrana entre lo visible que está y lo invisible en un espacio de inmanencia. En un poema de Jaime Sabines un personaje le pregunta al aire:

“Quién está ahí?

No estoy, soy le responde la muerte desde el vacío.

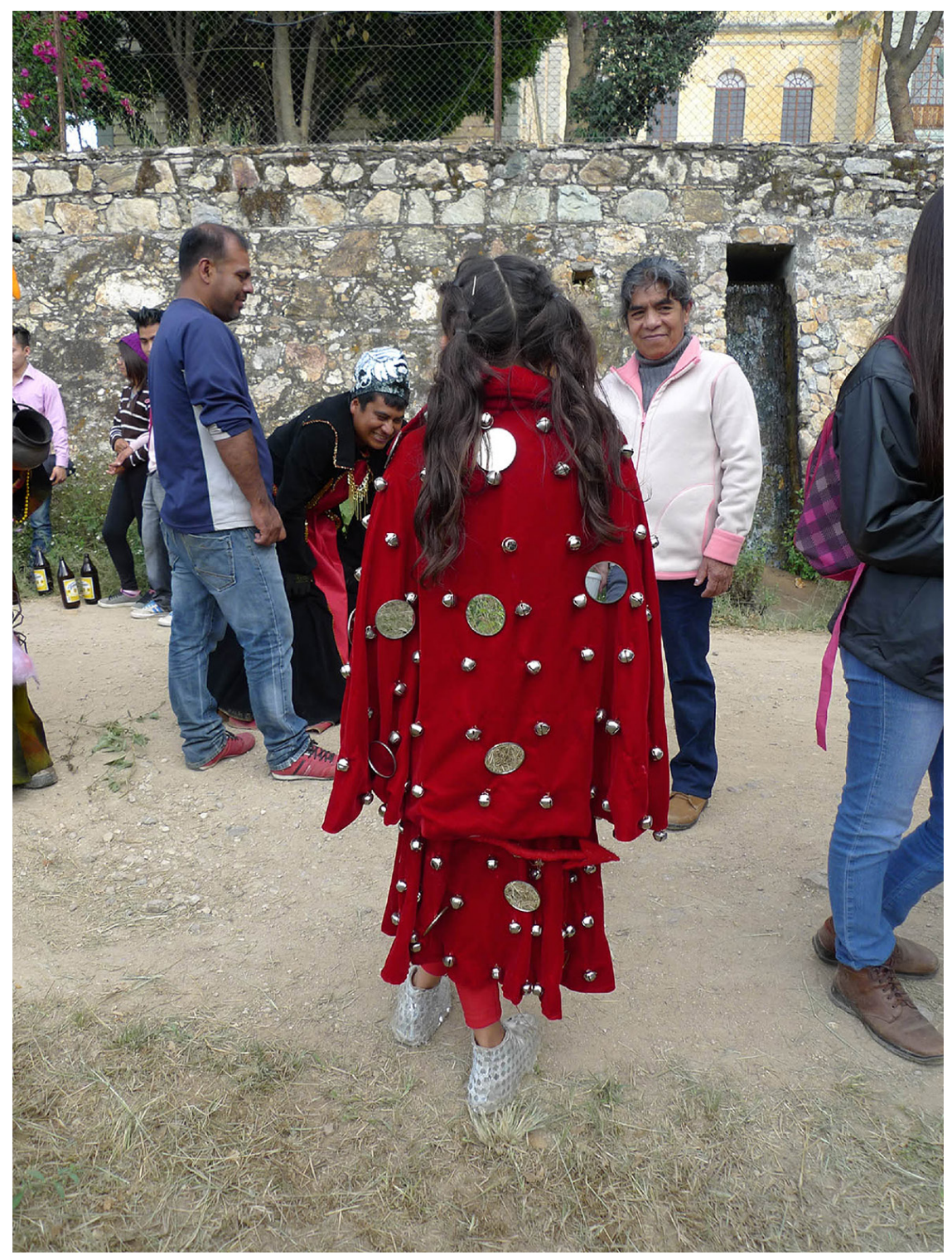

Figura 9 - Juan (Iván) González de León, 2015, Vestuario en festejo en Oaxaca.Tela, espejos, cascabeles, $160 \times 70 \mathrm{~cm}$. Fonte: Archivo del autor 


\section{Procesos de autoconstrucción}

Mientras reflexiono y escribo este texto no puedo dejar de pensar la afinidad que tengo con ciertos artistas brasileños, como con los dibujos de Tunga y la obra de Daniel Senise, así como la flora y fauna que dejó una impresión en mí cuando sobrevolé sobre Manaos y transité por la Mata Atlántica en camino a Sao Paolo. ¿Será porque siendo de este continente, la diacronía y no la sincronía es lo que se manifiesta constantemente? ¿O será una respuesta a una parte de nuestro glosario cultural o bien la necesidad de alejarse del agobiante aparato imperial de la lógica eurocéntrica? En todos los casos siempre hay en nuestras imágenes deslizamientos en dirección de lo no codificado en un lenguaje estrictamente occidental y representacional, una manera de sobrellevar la anamnesis en nuestra condición continental ${ }^{13}$

\section{Poscolonialismo o la reconciliación con estrategias culturales glocales}

En el proceso de reintegración a México en 1994, después de 10 años en Holanda, poco a poco fui dándome cuenta de lo siguiente; cada lugar tiene sus rutas lógicas pero también sensoriales. De cierta manera estas condiciones se me hicieron presentes y gradualmente, encontré referencias o me encontraron para hablar a través de mí. La semilla del cacao, el colibrí y la zomorfias populares como condición de empatía con lo natural son impresiones del exterior pero también explican parte de lo que soy. En las etapas de la vida el surgimiento, el tránsito por la vida y la reconciliación con la idea de que uno solo es un eslabón o un fruto temporal es conocimiento. Somos como sugiere Octavio Paz, "signos en rotación".

Nuestra realidad compartida siempre ha oscilado entre la influencia de lo global y la resistencia de lo local. Nuestro inconsciente colectivo siempre reclama nuestro pasado más arcaico y mientras al mismo tiempo nos proyectarnos hacia nuestro futuro más lejano. Esto en México sofoca y es dual, vivimos entre la negación y la autoafirmación de estereotipos y no a profundidad. Parece que estamos aún construyendo nuestras cadenas lingüísticas; y, iqué bueno!, somos todavía una cultura viva, en el devenir, entre sus huellas y marcas, redondeando sensaciones, ideando conceptos. Somos sujetos que se representan pero también se expresan. Reconfiguramos impresiones y experiencias. En lo político, la memoria siempre acechada por narrativas de exclusión resiste y cada ciertas generaciones es revisada y reseteada a conveniencia del régimen en turno. Sin embargo, es en la costumbre y el rito que se mantiene la resiliencia, de aquí mis imágenes.

13 En el contexto de la globalización, el término glocalización surgió de examinar el dilema dentro de la globalización que planteaba el ser igual y el mantener la diferencia entre culturas y las implicaciones de la interacción. El sociólogo Roland Robertson rechazó la tesis de una total homegenización e hizo énfasis en la cualidad del "préstamo cultural" entre culturas. De ahí la idea de la hibridización (STEGER, 2003, p. 75). 
En el terreno de lo sensible en México es vigente la noción del concepto náhuatl de "Ixiptla"14. La idea de que la imagen no es solo una representación, es también algo que se hace presencia, una invocación. Estas imágenes se deslizan entre la realidad y el espacio del espíritu, no son ídolos (eso es un reduccionismo excluyente); en este contexto del náhuatl las imágenes subrayan la inmanencia de las fuerzas que nos rodean, lo que tenemos aquí no es la representación de lo significado, es también su presencia, es hacerse manifiesto.

De una manera sintética, estas son quizá mis motivaciones y las presencias que acompañan mis imágenes, dibujos, gráfica y fotografía construida.

He comentado sobre la necesidad de justificarse desde la conceptualización teórica filosófica o desde el conocimiento; pero al final, la realización de toda obra ya en lo material del objeto pone de manifiesto otra serie de condiciones, contesta respuestas, pero en su génesis reconfigura nuevas preguntas. Comenté como el dibujo como huella, marca o símbolo cumplía con la función de ordenar el pensamiento en imágenes, que a su vez se trazaban sobre elementos figurativos, semillas, rostros, aves o signos comerciales. A su vez amplié sobre la poiesis y sus dilemas en la percepción de lo simbólico. Acabé por agregar algo sobre la noción de como el contexto cultural define en parte nuestra imaginación y nuestro modelo de percepción. Sin embargo al final, y la razón por la que dibujo, se encuentra dentro de los impulsos más innatos de nuestra creatividad: el adivinar. En el adivinar cerca de la idea de proyectar está la necesidad de invocar, agitar el pensamiento y asumir el dibujo como experiencia y poiesis.

14 Venimos acarreando una interpretación dudosa de la noción que tenemos del conjunto de imagen como la usaban los monjes franciscanos durante la evangelización, y de la interpretación que tenía el mundo náhuatl acerca de cómo apreciaba su lengua este concepto. Los antecedentes vienen desde la evangelización. Se relaciona el término del papel que juega la vestimenta en los rituales mexicas de "personificación" en los cuales confeccionaban con papel amate y motivos pictóricos para así transformarse en una encarnación divina. 


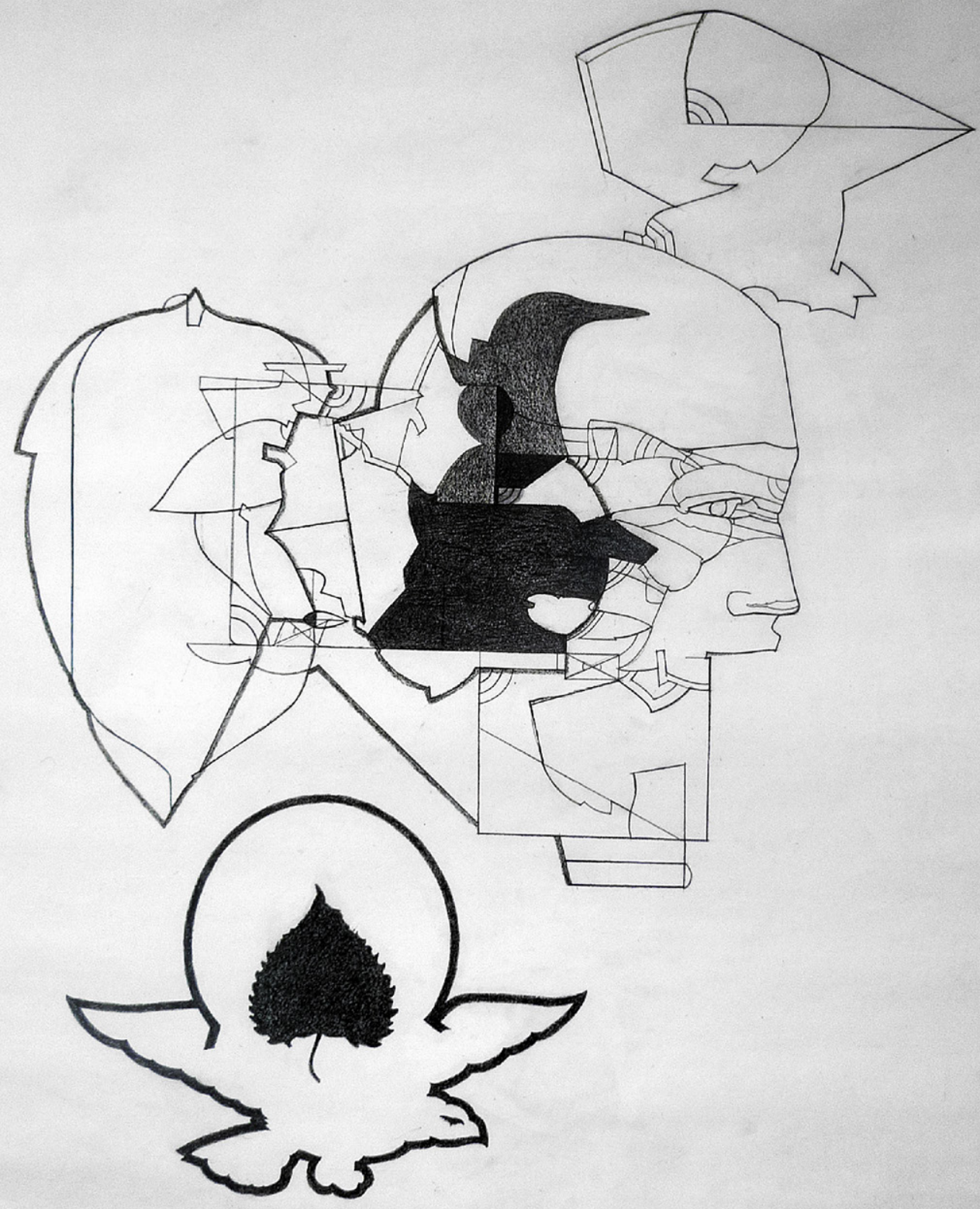

Figura 10 - Juan (Iván) González de León, 2021, Perfil recorte de prensa, dibujo, lápiz de cera sobre Papel Bond 200 grs., 110 x 76 cm. Fonte: Archivo del autor. 


\section{Referências}

AGUILAR, F. Z. Filosofía de la imagen. Lenguaje, imagen y representación, México: UNAM, 2008.

DELEUZE, G; GUATTARI, F.. On the line. 2a. ed. Colección Semiotext(E) Foreing Agent Series. Cambridge: The MIT Press, 1983.

LUPTON, E. Intuición, acción, creación. Graphic Design Thinking. Barcelona: Editorial Gustavo Gili, 2012.

STEGER, M. Globalization. A Very Short Introduction. Oxford: Oxford University Press, 2003.

OSBORNE, P. Conceptual Art. Phaidon, 2002. 


\section{Sobre o autor}

Juan (Iván) González de León, nasceu na Cidade do México em 1961. Graduou-se pela Escuela Nacional de Artes Plásticas da Universidad Nacional Autónoma de México (UNAM) e pós graduado pela Jan Van Eyck Academie, Holanda. É professor das disciplinas de produção poética e desenho da Escuela de Pintura, Escultura y Grabado La Esmeralda, vinculada ao Instituto Nacional de Bellas Artes y Literatura - INBAL. É membro do Sistema Nacional de Creadores de Arte.

enpeg.juangonzalezdeleon@inba.edu.mx

Recebido em: 09-03-2021

\section{Como citar}

DE LEÓN, Juan (Iván) González. (2021). El dibujo es un verbo. Revista Estado da Arte, Uberlândia. v.2, n.1, p. 107-127, jan./jun. 2021. https://doi.10.14393/EdA-v2-n1-2021-59885 